\title{
Evaluation of prolonged pain in preterm infants with pneumothorax using heart rate variability analysis and EDIN (Échelle Douleur Inconfort Nouveau-Né, neonatal pain and discomfort scale) scores
}

\author{
Mehmet Buyuktiryaki, MD', Nurdan Uras, MD', Nilufer Okur, MD', Mehmet Yekta Oncel, MD², Gulsum Kadioglu Simsek, MD', Sehribanu \\ Ozluer Isik, MD', Serife Suna Oguz, MD' \\ ${ }^{1}$ Division of Neonatology, Zekai Tahir Burak Maternity Teaching Hospital, Ankara, ${ }^{2}$ Division of Neonatology, Department of Pediatrics, Katip Çelebi University, Izmir, \\ Turkey
}

Purpose: The EDIN scale (Échelle Douleur Inconfort Nouveau-Né, neonatal pain and discomfort scale) and heart rate variability has been used for the evaluation of prolonged pain. The aim of our study was to assess the value of the newborn infant parasympathetic evaluation (NIPE) index and EDIN scale for the evaluation of prolonged pain in preterm infants with chest tube placement due to pneumothorax.

Methods: This prospective observational study assessed prolonged pain in preterm infants with a gestational age between 33 and 35 weeks undergoing installation of chest tubes. Prolonged pain was assessed using the EDIN scale and NIPE index.

Results: There was a significant correlation between the EDIN scale and NIPE index $(r=-0.590, P=$ 0.003). Prolonged pain is significantly more severe in the first 6 hours following chest tube installation (NIPE index: 60 [50-86] vs. 68 [45-89], $P<0.002$; EDIN score: 8 [7-11] vs. 6 [4-8], $P<0.001$ ).

Conclusion: Prolonged pain can be accurately assessed with the EDIN scale and NIPE index. However, evaluation with the EDIN scale is time-consuming. The NIPE index can provide instantaneous assessment of prolonged and continuous pain.

Key words: Infant, Premature, Pain, Pain measurement, Heart rate variability

\section{Introduction}

Newborns observed in the neonatal intensive care units (NICU) are exposed to painful interventions every day and this in turn affects their further developments. ${ }^{1,2)}$ Acute pain is the most common type of pain in NICU. Chronic pain is defined as pain that takes 3 months in children, whereas in the newborn, this period has not been defined yet. ${ }^{3)}$ Therefore, longterm pain in the newborn can be defined as prolonged pain. ${ }^{4-7)}$ Pain assessment in neonates is among the most difficult challenges faced by health professionals. The main goal in assessing the pain response is, infant's painful condition determination of the level of pain. ${ }^{8)}$ Exposure of the newborn to pain leads to negative effects, both in the short- and long terms. ${ }^{2,9,10)}$ It is difficult to define prolonged pain compared to the acute pain, and thus it may not be treated. Pain relief is the primary issue in the newborn intensive care units. Correct evaluation of the pain provides correct determination of the analgesic need and the efficacy of the analgesics. ${ }^{11)}$
Corresponding author: Mehmet Buyuktiryaki, MD Division of Neonatology, Zekai Tahir Burak Maternity Teaching Hospital, Altındağ, 06230, Ankara, Turkey

Tel: +90-3123065270

Fax: $+90-3123114645$

E-mail: mbuyuktiryaki@yahoo.com

https://orcid.org/0000-0001-8937-4671

Received: 18 August, 2017

Revised: 2 July, 2018

Accepted: 16 July, 2018

Copyright ( 2018 by The Korean Pediatric Society

This is an open-access article distributed under the terms of the Creative Commons Attribution NonCommercial License (http://creativecommons.org/ licenses/by-nc/4.0// which permits unrestricted noncommercial use, distribution, and reproduction in any medium, provided the original work is properly cited. 
Acute pain may be assessed via many different tools, although a limited number of scoring systems are available to assess prolonged pain. Among these, the EDIN scale (Échelle Douleur Inconfort Nouveau-Né, neonatal pain and discomfort scale) is the most commonly used scoring system that assesses prolonged pain in preterm infants using five different behavioral elements.5) In practice, the EDIN scale may be used 2 or 3 times daily at the NICU, and it may show variations between observations. Despite the availability of methods assessing prolonged pain such as the approved EDIN scale, the need for new methods has continued due to its long observation time and its inability to detect pain severity fluctuations. $^{12,13)}$

The physiological effects of painful stimuli arise through the autonomic nervous system (ANS). ${ }^{12)}$ Heart rate variability (HRV), parasympathetic and sympathetic transmission from the central nervous system to the sinoatrial nodule due to differences in levels. ${ }^{13)}$ Changes in parasympathetic stimulation that are particularly effective at HRV. HRV is a well-established non-invasive measure of cardiac autonomic control. ${ }^{14)}$ Previous studies have shown that painful stimuli cause a decrease in parasympathetic stimulation and thus a decrease in HRV. ${ }^{13-15)}$ The Newborn Infant Parasympathetic Evaluation (NIPE) monitor, based on HRV analysis, has been developed specifically for prolonged pain detection and continuous monitoring. ${ }^{12)}$ Ultimately, the NIPE index assesses parasympathetic excitability and may be a good decision aid for pain assessment for health professionals. ${ }^{12-15)}$

The aim of this study was to evaluate prolonged pain in premature infants undergoing chest tube installation due to pneumothorax using the EDIN scale and the NIPE index, and to compare the correlations between the 2 methods.

\section{Materials and methods}

\section{Study population}

This prospective and observational study was conducted at the NICU in Zekai Tahir Burak Hospital between February 1, 2015 and July 30, 2016. Premature infants with a gestational age of between 33 and 35 weeks undergoing chest tube installation due to pneumothorax were included in the study. Patients with circulatory system disorders necessitating vasopressor drug administration, a need for mechanical ventilation, congenital abnormalities, severe cardiac malformation and parents do not allow were excluded from the study. The release of this study and the data was approved by the local ethics committee, and all parents of the studied babies gave informed consent for data analysis and data publication.

\section{Study protocol}

Patients included in the study were administered fentanyl $1 \mu \mathrm{gg} / \mathrm{kg}$ IV (over at least 5 minutes) and subcutaneous lidocaine 1\% $2 \mathrm{mg} /$ $\mathrm{kg}$ buffered with sodium bicarbonate (1:10) 2 minutes prior to chest tube placement. ${ }^{11)}$ The 8 -Fr chest tube is placed in the midaxillary line 4-5, intercostal space. Then, fentanyl $1 \mu \mathrm{g} / \mathrm{kg}$ was continued once every 6 hours, and pain monitoring was performed via the EDIN scale and the NIPE monitoring.

\section{NIPE monitor}

The NIPE monitor (Mdoloris Medical Systems, Lille, France) is designed to assess HRV. The NIPE index is based on continuous cardiac signal (electrocardiography or plethysmographic waveform) processing. The detection of each heartbeat is realized and the RR series is computed as the time evolution of the period between 2 heart beats. The RR series are resampled at $8 \mathrm{~Hz}$ and the mean centered and normalized in a 64-second moving window. ${ }^{12)} \mathrm{A}$ wavelength-based high pass filter over $0.15 \mathrm{~Hz}$ is applied in order to keep parasympathetic-related variations only, which are mainly affected by the respiration cycle. Following the RR filtering, local maxima and minima are determined in the 64-second window. Lower and upper envelopes are plotted in order to compute 4 areas under the curves (AUC) (one area/16 seconds: A1, A2, A3, and A4). AUC min is detected as the minimum value of $\mathrm{A} 1, \mathrm{~A} 2, \mathrm{~A} 3$, and $\mathrm{A} 4$. In order to obtain a value normalized between 0 and 100, it has been defined as the NIPE index: NIPE $=100 *(5.1 * \mathrm{AUCmin}+1.2) / 12.8$, where 12.8 corresponds to the maximum AUC value $(\mathrm{A} 1+\mathrm{A} 2+$ $\mathrm{A} 3+\mathrm{A} 4=64 \times 0.2=12.8 \mathrm{cf}$.) and where the linear equation's values (5.1 and 1.2) were defined empirically on a 200-patient population in order to keep a good correlation between the visual information and the numerical value.

In clinical practice, a NIPE close to 100 corresponds to a high level of comfort. On the opposite, a NIPE close to 0 can be interpreted as a very low comfort level, which could be related to a high stress level. ${ }^{12)}$ The algorithm is computed continuously by sliding the moving window with a 1-second moving period. NIPEm is then computed as the record's last 20 minutes mean value, but the software also gives a value of instantaneous NIPE for short-term analysis of neonatal high frequencies HRV. The mean NIPE scores were assessed every twenty minutes and the mean values were recorded for each hour in the first 12 hours.

\section{EDIN scale}

The EDIN scale uses 5 behavioral indicators of prolonged pain: facial activity, body movements, quality of sleep, quality of contact with nurses, and consolability. ${ }^{8}$ Each indicator is scored from 0 to 3 and the EDIN scale is the sum of the five items; that is, the final score ranges from 0 to $15 .^{5)}$ An EDIN score of $>6$ demonstrates the presence of marked pain clinically. ${ }^{16)}$ At the end of a 6-hout observation period, the nurses calculate the EDIN score while performing their duties. 


\section{Statistical analysis}

Statistical analyses were performed using the IBM SPSS Statistics ver. 21.0 (IBM Co., Armonk, NY, USA). The descriptive data for categorical variables were given as frequencies $(\%)$ and for continuous variables as median (interquartile range) or mean ( \pm standard deviation) as appropriate. Mann-Whitney $U$ test was used for the comparison of nonnormally distributed variables. While investigating the association between EDIN scale and NIPE index, Spearman correlation test was used. A $P$ value of $<0.05$ was considered statistically significant.

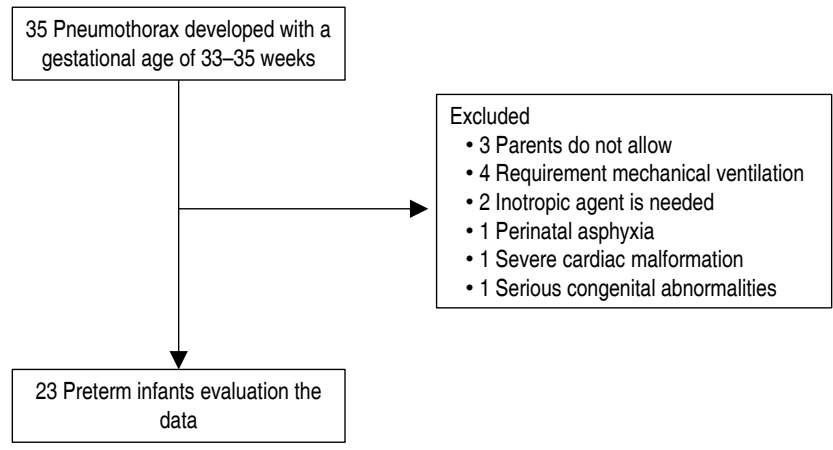

Fig. 1. Study population.

Table 1. Demographic and clinical characteristics of study groups

\begin{tabular}{lc}
\hline Characteristic & Value \\
\hline Gestational age (wk) & $34 \pm 0.8$ \\
Birth weight (g) & $2,524 \pm 552$ \\
Male sex & $18(78.3)$ \\
Caesarean delivery & $22(95.7)$ \\
Apgar score at 5 minutes & $7(5-9)$ \\
Resuscitation at delivery room & $5(21.7)$ \\
Time of pneumothorax occurence (hours of age) & $37(7-61)$ \\
\hline
\end{tabular}

Values are presented as mean \pm standard deviation, number (\%), or median (range).

\section{Results}

A total of 23 preterm infants were included in the study (Fig. 1). The patient characteristics have been presented in Table 1 . The mean gestational week of the infants was $34 \pm 20.8$ weeks and the mean birth weight was $2,524 \pm 552 \mathrm{~g}$. Five preterm infants (21.7\%) had undergone positive pressure ventilation after birth. The median time for development of pneumothorax and chest tube installation in the study group was 37 (7-61) hours of age (Table 1).

The median NIPE index within the first 6 hours after chest tube installation was 60 (50-86), and it was 68 (45-89) within the second 6 hours $(P<0.002)$. The median EDIN score within the first 6 hours was $8(7-11)$, and it was $6(4-8)$ in the second 6 hours $(P<0.001)$ (Table 2). A significant negative correlation was determined between the EDIN scale and the NIPE index measured within both 6-hour periods $(r=-0.590, P=0.003)$.

\section{Discussion}

We aimed to evaluate the pain level using the NIPE monitoring and the NIPE index that has been developed recently, and the EDIN scale, which is a classical method in premature infants undergoing chest tube installation due to pneumothorax. We recorded the highest pain levels within the first 6 hours following chest tube installation. A significant negative correlation was observed between the NIPE index and the EDIN score during the course of the chest tube. We concluded that NIPE monitoring is a reliable method in monitoring of prolonged pain. Within the second 6-hour-period after chest tube installation, the EDIN scores were decreased and the NIPE indexes were increased. This was evaluated as adaptation to pain and relieved comfort in response to the administered analgesics.

The number of studies evaluating pain observed as a result of treatment in the newborn with respiratory distress is limited in the literature. In a study investigating the effect of fentanyl infusion on acute and prolonged pain in preterm infants receiving mechanical

Table 2. Comparison of EDIN scale and NIPE monitor values

\begin{tabular}{|c|c|c|c|c|c|c|}
\hline & EDIN-1 & EDIN-2 & $P$ value & NIPE-1 & NIPE-2 & $P$ value \\
\hline Chest tube installation & $8(7-11)$ & $6(4-8)$ & $<0.001$ & $60(50-86)$ & 68 (45-89) & $<0.002$ \\
\hline First hour & - & - & - & $58(50-86)$ & 70 (55-89) & $<0.001$ \\
\hline Second hour & - & - & - & $61(50-78)$ & $63(45-78)$ & 0.55 \\
\hline Third hour & - & - & - & $63(52-80)$ & $66(51-81)$ & 0.20 \\
\hline Fourth hour & - & - & - & $64(51-81)$ & 67 (52-79) & 0.12 \\
\hline Fifth hour & - & - & - & $64(53-86)$ & 69 (53-78) & 0.01 \\
\hline Sixth hour & - & - & - & $56(50-79)$ & $72(54-89)$ & $<0.001$ \\
\hline
\end{tabular}

Values are presented as median (range).

EDIN (Échelle Douleur Inconfort Nouveau-Né, neonatal pain and discomfort scale), NIPE (Newborn Infant Parasympathetic Evaluation monitor); EDIN-1, EDIN value in the first 6 hours after chest tube insertion; EDIN-2, EDIN value in the second 6 hours after chest tube insertion; NIPE-1; NIPE value in the first 6 hours after chest tube insertion; NIPE-2, The NIPE value in the second 6 hours after chest tube insertion. 
ventilation, fentanyl was shown to reduce acute pain but not affect prolonged pain. However, severe prolonged pain (EDIN score of $>6$ ) in the placebo group was found to be significantly high compared to the fentanyl group. ${ }^{17)}$ In our study the EDIN score in the first 6 hours was found to be high showing prolonged pain.

The EDIN scale is affected by gestational age and postnatal age. Passing from 32 and 37 weeks to 37 weeks and higher results in a 1-point increase in the scale. Likewise, the EDIN score significantly increases with the increase in postnatal age between 0,60 , and 120 days. Furthermore, the need for respiratory support, sepsis and surgical operations affects the EDIN score to be $>6 .{ }^{11)}$ The preterm infants included in our study had close gestational ages and similar characteristics.

Studies suggesting that pain should be one of the monitoring parameters in NICU have demonstrated that prolonged pain could be assessed using HRV. ${ }^{12,13,15)}$ It has been shown in these studies that pain perception centers in the brain are associated with the centers regulating cardiovascular functions. ${ }^{18,19)}$ Neurons that receive nociceptive impulses and those that start autonomic responses are close to each other in most regions of the brain, and they are related to each other in central and peripheral levels. ${ }^{19)}$ Painful or stress stimuli affect the physiological functions via the effect of the ANS. The real time effect of ANS on body regulation may be monitored via HRV. HRV is a well-constructed noninvasive measuring method for cardiac autonomic control. ${ }^{14,18)} \mathrm{HRV}$ is formed by altered parasympathetic and sympathetic stimuli levels from the central nervous system to the sinoatrial node of the heart. In particular, the changes in the parasympathetic outflow lead to major changes in HRV. Parasympathetic and sympathetic outflows lead to a lower number of changes in HRV ${ }^{20)}$ A parasympathetic stimulus decreases during painful stimuli in infants. ${ }^{18)}$ The decreased parasympathetic stimulus results in reduced HRV. It has been determined in the study of Smith et al. ${ }^{21)}$ that massage leads to comfort and an increase in HRV in preterm infants. In another study, an increase in HRV was observed during kangaroo care for heel puncture in preterm infants. ${ }^{22)}$

In 2 different studies of De Jonckheere et al. ${ }^{13)}$ and Faye et al., ${ }^{15)}$ a decreased HRV was observed in high EDIN score that indicates prolonged pain, and an increased HRV was observed in low EDIN score. It has been reported that the decrease in $\mathrm{HRV}$ is a good indicator of prolonged pain, and that HRV analysis and the EDIN scale are correlated. ${ }^{13,15}$ Subsequently, the NIPE Monitor was developed by Butruille et al. ${ }^{12}$ in order to monitor the real time prolonged pain. In the study of Butruille et al. ${ }^{12)}$ infants with a gestational age longer than 34 weeks were divided into 2 groups as low and high EDIN groups following a major surgical operation, and the NIPE index was found to be significantly low in the high EDIN group, which indicated a decreased HRV. Furthermore, a significant negative correlation was determined between the EDIN score and the NIPE index. Similar to the studies of De Jonckheere et al. ${ }^{13)}$, Faye et al., ${ }^{15)}$ and Butruille et al., ${ }^{12)}$ a significant decrease was determined in the high EDIN scores that indicate prolonged pain and a negative correlation between the NIPE index and the EDIN score in our study. Considering the data obtained in our study, we believe that NIPE monitoring is an effective and reliable method in the evaluation of painful interventions.

The most important advantage of the NIPE monitor from the EDIN scale is that it is possible to assess prolonged pain in a very short period of time. It also provides instant and continuous evaluation. The NIPE monitor is a noninvasive method that provides objective data in assessing prolonged pain to clinicians. Since environmental factors affect HRV, similar environmental conditions must be provided for monitoring the baby. Factors such as age of pregnancy and drug use also affect HRV. However, even in such a case, continuous monitoring with the NIPE monitor can cause the NIPE index to decrease if there is prolonged pain. However, in order to fully determine the effect of these conditions, it will be the end result of studies that will include newborns at different gestational ages or who use and do not use medicines that affect HRV.

The NIPE index that is used in our study may be affected by various environmental factors. HRV is controlled by the ANS outflow, which is altered by numerous factors including maturation, environmental conditions or drugs. ${ }^{11)}$ However, the environmental conditions were strictly controlled in our study. Furthermore, the sample size of the study was small. However, the data obtained are of clinical practical value.

Prolonged pain can be accurately assessed via EDIN scale and NIPE monitors. However, a long time period is required for evaluation with the EDIN scale. With the NIPE monitors, instantaneous and continuous prolonged pain can be assessed.

\section{Conflicts of interest}

No potential conflict of interest relevant to this article was reported.

\section{References}

1. Hall RW, Anand KJ. Physiology of pain and stress in the newborn. NeoReviews 2005;2:e61-8.

2. Carbajal R, Rousset A, Danan C, Coquery S, Nolent P, Ducrocq S, et al. Epidemiology and treatment of painful procedures in neonates in intensive care units. JAMA 2008;300:60-70.

3. Apkarian AV, Baliki MN, Geha PY. Towards a theory of chronic pain. Prog Neurobiol 2009;87:81-97.

4. van Ganzewinkel CJ, Anand KJ, Kramer BW, Andriessen P. Chronic pain in the newborn: toward a definition. Clin J Pain 2014;30:970-7.

5. Debillon T, Zupan V, Ravault N, Magny JF, Dehan M. Development and initial validation of the EDIN scale, a new tool for assessing prolonged pain in preterm infants. Arch Dis Child Fetal Neonatal Ed 2001;85:F36-41. 
6. Hummel P, Puchalski M, Creech SD, Weiss MG. Clinical reliability and validity of the N-PASS: neonatal pain, agitation and sedation scale with prolonged pain. J Perinatol 2008;28:55-60.

7. van Dijk M, Roofthooft DW, Anand KJ, Guldemond F, de Graaf J, Simons $\mathrm{S}$, et al. Taking up the challenge of measuring prolonged pain in (premature) neonates: the COMFORTneo scale seems promising. Clin J Pain 2009;25:607-16.

8. Walter-Nicolet E, Annequin D, Biran V, Mitanchez D, Tourniaire B. Pain management in newborns: from prevention to treatment. Paediatr Drugs 2010;12:353-65.

9. Lidow MS. Long-term effects of neonatal pain on nociceptive systems. Pain 2002;99:377-83.

10. Grunau RE, Holsti L, Peters JW. Long-term consequences of pain in human neonates. Semin Fetal Neonatal Med 2006;11:268-75.

11. Committee on Fetus and Newborn and Section on Anesthesiology and Pain Medicine. Prevention and management of procedural pain in the neonate: an update. Pediatrics 2016;137:e20154271.

12. Butruille L, Jonckheere JD, Marcilly R, Boog C, Bras da Costa S, Rakza $\mathrm{T}$, et al. Development of a pain monitoring device focused on newborn infant applications: The Neo Doloris Project. IRBM 2015;36:805.

13. De Jonckheere J, Rakza T, Logier R, Jeanne M, Jounwaz R, Storme L. Heart rate variability analysis for newborn infants prolonged pain assessment. Conf Proc IEEE Eng Med Biol Soc 2011;2011:7747-50.

14. Schäffer L, Burkhardt T, Müller-Vizentini D, Rauh M, Tomaske M, Mieth RA, et al. Cardiac autonomic balance in small-for-gestational- age neonates. Am J Physiol Heart Circ Physiol 2008;294:H884-90.

15. Faye PM, De Jonckheere J, Logier R, Kuissi E, Jeanne M, Rakza T, et al. Newborn infant pain assessment using heart rate variability analysis. Clin J Pain 2010;26:777-82.

16. Ancora G, Mastrocola M, Bagnara C, Zola D, Pierantoni L, Rossi G, et al. Influence of gestational age on the EDIN score: an observational study. Arch Dis Child Fetal Neonatal Ed 2009;94:F35-8.

17. Ancora G, Lago P, Garetti E, Pirelli A, Merazzi D, Mastrocola M, et al. Efficacy and safety of continuous infusion of fentanyl for pain control in preterm newborns on mechanical ventilation. J Pediatr 2013; 163:645-51.e1.

18. Oberlander TF, Grunau RE, Pitfield S, Whitfield MF, Saul JP. The developmental character of cardiac autonomic responses to an acute noxious event in 4- and 8-month-old healthy infants. Pediatr Res 1999;45(4 Pt 1):519-25.

19. Benarroch EE. Pain-autonomic interactions. Neurol Sci 2006;27 Suppl 2:S130-3.

20. Parati G, Mancia G, Di Rienzo M, Castiglioni P. Point: cardiovascular variability is/is not an index of autonomic control of circulation. J Appl Physiol (1985) 2006;101:676-8.

21. Smith SL, Lux R, Haley S, Slater H, Beachy J, Moyer-Mileur LJ. The effect of massage on heart rate variability in preterm infants. J Perinatol 2013;33:59-64.

22. Cong X, Ludington-Hoe SM, McCain G, Fu P. Kangaroo Care modifies preterm infant heart rate variability in response to heel stick pain: pilot study. Early Hum Dev 2009;85:561-7. 